\section{Stroke in neurological services in Italy}

Fabrizio Antonio de Falco,' Maurizio A. Leone, ${ }^{2,3}$ Ettore Beghi ${ }^{3}$ on behalf of the NEU Project Group

'Neurology Unit, "Loreto Nuovo" Hospital, Naples, Italy; ${ }^{2} \mathrm{Clinica}$ Neurologica, AOU "Maggiore della Carità", Novara, Italy; ${ }^{3}$ Neurology Laboratory, "Mario Negri" Institute, Milan, Italy

\section{Abstract}

To assess the stroke workload of Italian neurological services and to correlate it with indicators of each hospital's emergency setting. A semi-structured questionnaire was sent to the 220 neurology units (NU) located in hospitals with an emergency room (ER) (155 responders, 71\%). Stroke was the most common discharge diagnosis (29\%) (273 patients/year/NU on average) and condition requiring consultation in ER (28\%). A stroke unit was available in $28 \%$ of NU, bedside monitors in $45 \%$, a 24 hour/day and 7 day/week (24/7) CT scan in $90 \%$, a $24 / 7$-MRI in $32 \%$, a $24 / 7$ on-duty neurologist in $36 \%$. The stroke workload was correlated only with the number of ER consultations per year, and marginally to the presence of stroke units and the number of monitored beds in the univariate, but not in the multivariate analysis. The stroke workload in Italian NU is very high, but is largely unrelated to their structural and functional characteristics, in contrast with the international indications requiring several essential criteria for the best hospital management of all stroke patients.

\section{Introduction}

Stroke is a clinical emergency that commonly results in admission to an emergency room (ER), and is frequently associated with high mortality and the costs imposed by acute management and long-term care. Advances in neuroimaging and the introduction of new treatments to be started in the ER, have changed the diagnostic and therapeutic approach to acute cerebrovascular diseases ${ }^{1,2}$ and led to the establishment of stroke units in several parts of Italy. ${ }^{3}$

Stroke is the most frequent cause of neurological admission to an ER..$^{46}$ In Italy, hospital discharges for neurological non-surgical diseases [(Diagnosis Related Groups (DRG) 935 )] were 554,872 ( $7 \%$ of the total) in $2003 .{ }^{7}$
Stroke (DRG 14) accounted for $22 \%$ of all neurological discharges, and was the sixth most common hospital discharge diagnosis (HDD) $(n=123,310)$, even more common than acute myocardial infarction $(\mathrm{n}=114,632)$. In 2005, hospital discharges for stroke were 129,203. ${ }^{8}$

According to a WHO/WFN survey, acute cerebrovascular diseases are a main cause of neurological workload in primary care worldwide, but the resources available to cope with this burden are very often inadequate. ${ }^{9}$ In Europe, hospital services admitting acute stroke patients have been classed by an expert panel as: Comprehensive Stroke Centers (CSC), Primary Stroke Centers (PSC) and Any Hospital Wards (AHW) in terms of their structural, technological and human resources..$^{10} \mathrm{~A}$ survey of 886 European hospitals treating stroke patients found that only $14 \%$ of strokes were treated in CSC or PSC, 44\% in AHW, and $42 \%$ in facilities not even meeting minimal criteria. ${ }^{11}$ Only $30 \%$ of the hospitals with at least one neurologist have a stroke unit in France. ${ }^{12}$ Only $30 \%$ of all strokes are treated in stroke units in Germany, ${ }^{13}$ and $27 \%$ in the UK, even though stroke units have been established in $75 \%$ of the hospitals that treat stroke patients in that country. ${ }^{14}$ In the same surveys, only $11 \%$ of the French hospitals have a 24-hour/day and 7 day/week (24/7) coverage by on-duty neurologists, and a neurologist was available on average twice a week in the UK.

In the years 2001-2003, we undertook a nationwide survey to determine the extent of involvement of Italian neurologists in ER activities. ${ }^{15}$ This paper reviews our stroke data for the purpose of: 1) calculating the stroke workload for neurologists, and 2) assessing whether and to what extent stroke workload is correlated with a number of indicators of each hospital's emergency setting.

\section{Materials and Methods}

The survey was endorsed by the two Italian neurological societies (Società Italiana di Neurologia and Società dei Neurologi, Neurochirurghi e Neuroradiologi Ospedalieri). Socio-economic and health organization settings were compared by dividing the country into four major areas and appointing regional coordinators. In the first phase of the survey (September 2001 to September 2002), all the hospitals with neurological facilities were identified, those with an ER were selected, and a neurologist in each Neurology Unit (NU) was identified as a contact. NU were defined as wards dedicated to the care of neurological patients; in Italy they are managed only by neurologists. In the second phase (October 2002 to June 2003), a semi-structured questionnaire was sent to selected NUs to collect
Correspondence: Fabrizio Antonio de Falco, Neurology Unit, "Loreto Nuovo" Hospital, via Vespucci 15, 80121 Naples, Italy.

E-mail: defalco@tin.it

Key words: stroke, neurology services, neurologist, emergency service hospitals, workload.

Acknowledgments: we wish to thank the regional coordinators (Roberto Sterzi, Milan; Vito Toso, Vicenza; Domenico Consoli, Vibo Valentia, Donata Guidetti, Piacenza; Leandro Provinciali, Ancona) and the "Società Italiana di Neurologia" (SIN) for supporting this project.

This research was carried out at the Neurology Laboratory, "Mario Negri" Institute, Milan, Italy.

Received for publication: 2 March 2009.

Revision received: 13 June 2009.

Accepted for publication: 19 July 2009.

This work is licensed under a Creative Commons Attribution 3.0 License (by-nc 3.0)

(C) Copyright F.A. de Falco et al., 2009

Licensee PAGEPress, Italy

Neurology International 2009; 1:e8

doi:10.4081/ni.2009.e8

information about hospital settings, structural characteristics of each $\mathrm{NU}$, and clinical activities. Each regional coordinator supervised the completeness and quality of the information provided.

The hospitals were differentiated in accordance with five categories:

- location: North-West, North-East, Central, and South/Islands;

- size: $\leq 300 ; 301-800 ;>800$ beds;

- functional context: university hospital and scientific institutes vs. general and local hospitals (general hospitals have their own management, whereas local hospitals are part of the local Health Care District);

- structural context: presence of a neuroscience or internal medicine department;

- ER organization: classed according to the complexity of the emergency department (ED) as: structural (ED-II), functional (ED-I) or First Aid Service (FAS). ED-II are autonomous structures with their own beds and medical and nursing staff; ED-I do not have dedicated beds and share medical staff with other departments; FAS are nonautonomous services in small hospitals with rotation of medical and nursing hospital staff. The resources and activities of each $\mathrm{NU}$ were evaluated on the basis of a number of structural and activity indicators:

- structure indicators: structure of the $\mathrm{NU}$ (staff, number of beds and bedside monitors, on-duty and on-call neurologist) and hospital setting (presence of intensive care, 
neurosurgery and emergency medicine wards or departments and stroke unit i.e. a structurally defined area of the NU for care of stroke patients by a dedicated team; availability of EEG, CT scan, MRI)

- activity indicators: ER admissions to the NU (number and DRG, admissions for stroke) and neurological ER consultations (number and clinical diagnosis)

The indicator values were grouped in categories defined by the median (above or below), and by tertiles and quartiles. The only exception was the number of beds, for which the category $<10$ was devised.

The stroke burden was defined as the number of hospitalized strokes (ischemic and hemorrhagic) per year; as this number may depend on the hospital size and the total number of admissions, the relative stroke workload was calculated as (number of strokes/year)/(number of total admissions/year)*100, and assigned to three categories, $\leq 20 \%, 21-40 \%$, and $>40 \%$. Admission data were obtained from hospital computerized databases $(n=107)$, or transcribed from inpatient registries $(n=41)$; the data source was not specified by 11 hospitals. Statistics were elaborated with Student's test, $\mathrm{X}^{2}$ test, $\mathrm{X}^{2}$ test for trend and Pearson's correlation coefficient where applicable. Bonferroni's correction for multiple testing was used, setting the $p$ at 0.01 for correlations with the five main hospital categories (location, size, functional and structural context, and ER organization) and at 0.005 for the correlations with the other indicators. All the tests were performed with the statistical package SAS. ${ }^{16}$ A multivariable analysis with a binary logistic regression model was used to control for confounders and interactions (SAS/PROC Logistic). The relative stroke workload was the response variable and location, size, functional and structural context, ER organization, and the structure and activity indicators were used as covariates.

\section{Results}

Two hundred and sixty-four hospitals with an NU were identified in the entire country. All but two were general, acute-care public hospital funded by the National Health Care System. Two hundred and twenty (84\%) had an ER; they had a total of 5,518 neurological beds (96/1,000,000 population) and 1,623 staff neurologists (28/1,000,000 population). Of the 220 questionnaires sent out, 159 were returned, and the number of stroke admissions/year was available for 155 (71\%). Data for some variables were not supplied by ten NU (6\%) (Tables 1 and 2). There were no significant differences in the hospital categories between the 155 with and the 65 without available information (data not shown). The mean catchment area of the 155 hospitals was 270,000 population (range 50,000-1,500,000), and the mean number of beds was 627 ( $\mathrm{SD}=411$, range 141-2,650). Each NU had an average of 25 beds ( $\mathrm{SD}=12$; range $=2-68$ ); monitoring was available for $7 \%$ of the total number of beds; the average number of neurologists per $\mathrm{NU}$ was 7 ( $\mathrm{SD}=3$; range $=2-18$ ) and that of nurses 17 ( $\mathrm{SD}=6$; range $=2-42$ ). The total number of admissions was 144,261 (mean 931, SD=430; range $=126-2,595$ ), $71 \%$ from the ER (range 18-100). A 24/7 CT-scan was available for 140/155 NU (90\%), a 24/7 MRI for $49 / 155$ (32\%), a $24 / 7$ on-duty neurologist in 56/154 (36\%) and a 24/7 neurologist (either on-duty or on-call) in 128/154 (83\%).

\section{Stroke burden and relative stroke workload}

Stroke was the commonest DRG in $124 \mathrm{NU}$ $(80 \%)$ and the most frequent cause of neurological consultation to ER in $46 \%$ of the $145 \mathrm{NU}$ supplying data for this variable. The total number of stroke patients/year admitted by NU (stroke burden) was 42,361 (29\% of total admissions) with a mean of $273(\mathrm{SD}=164$, range=14-904). Sixteen NU (10\%) admitted $\leq 100$ strokes, 45 (29\%) 101-200 strokes, 41 (27\%) 201-300, 28 (18\%) 301-400, 25 (16\%) $>400$ strokes. The relative stroke workload ranged from $2 \%$ to $82 \%$ of total admissions (median 26\%). Thirty-six NU (23\%) had a relative stroke workload of $\leq 20 \%, 88$ (57\%) 21 $40 \%$, and $31(20 \%)>40 \%$.

\section{Correlation with structural and activity indicators}

A stroke unit was present in $42 / 150 \mathrm{NU}$ (28\%), and 69/155 NU (45\%) had monitored beds with no correlation with the area, the size of the hospital, the structural and functional context and the ER organization. An intensive care unit was present in 149/155 hospitals (96\%), and correlated only with the hospital size (>800 beds: $29 \mathrm{NU}, 100 \%$; 301-800: 95, $100 \%$; $\leq 300: 21,78 \% ; p<0.0001$. The burden of stroke was correlated only to the number of hospital beds, neurologists, NU admissions, and ER consultations (Table 1). The relative stroke workload was correlated only with the number of ER consultations/year and marginally in the trend analysis to the presence of stroke units and the number of monitored beds (Table 2). However, these variables lost statistical significance in the multivariate model after adjusting for the five hospital categories. The Odds Ratio (95\% Confidence Limits) of a relative stroke workload $\leq 40$ versus $>40 \%$ was 1.8 (0.6-5.7) for $\leq 2.000$ ER consultations/ year versus >2.000; $1.8(0.5-7.2)$ for $\mathrm{NU}$ without a stroke unit; 4.1 (0.7-25.6) for no monitored beds versus $>4$; $1.2(0.3-5.81)$ for $1-4$ moni- tored bed versus $>4$. These results were virtually unchanged when models with a different cut-off (20\%) or addition of the other indicators were used.

\section{Discussion}

Eighty-four percent of Italian NU are located in hospitals with ER, where stroke is the commonest reason for ER neurological admission (almost $30 \%$ of total admissions in the NU providing data for our survey). In other European countries, admissions for stroke ranged from $25-33 \%{ }^{4-6}$ DRG14 was the first discharge diagnosis in $80 \%$ of $\mathrm{NU}$, and stroke was the most frequent reason for ER consultation in $46 \%$ of NU. Thus, stroke accounts for roughly one third of the workload of an Italian NU (see ref. 15 for the frequency of other neurological diseases).

We looked to see whether specific structural and activity, hospital or NU characteristics were correlated with the stroke burden and whether the higher relative stroke workload corresponded to a specific NU organization. However, except for the number of beds, neurologists, NU admissions, and ER consultations (all these variables being linked to the size and the general workload of each NU), there was no correlation between the hospital (and NU) structural and functional organization and the number of hospitalizations for stroke. In addition, the relative stroke workload was correlated only to the number of ER consultations and, marginally, to the presence of stroke units and the number of monitored beds in the univariate but not in the multivariate analysis.

Our observations indicate that the stroke workload is largely unrelated to a hospital's efficiency and sophistication, in contrast with the indications given by a panel of European experts, who advocated several essential components of organized acute stroke care, including personnel, diagnostic procedures, monitoring, and ad hoc protocols and procedures. ${ }^{10}$ However, our data are in keeping with the EUSI survey of 886 European hospitals showing that $42 \%$ of strokes were treated in facilities not even meeting the minimal criteria ${ }^{11}$ and with a survey of acute stroke care in Europe, which showed no difference between Eastern and Western Europe in a number of quality indicators, with the exception of technological standards in some countries. ${ }^{17}$

Some aspects of our survey suggest ways to improve the quality of stroke care in Italy. First, $10 \%$ of NU still do not have CT scan $24 / 7$ coverage which is considered an important requirement even for general (non-neurological) wards and an essential requirement for PSC. ${ }^{11}$ Indeed, CT 24/7 was most frequently unavail- 
Table 1. Hospital categories and structure-activity indicators by stroke burden (number of admissions for stroke/year to each NU) (N=155).

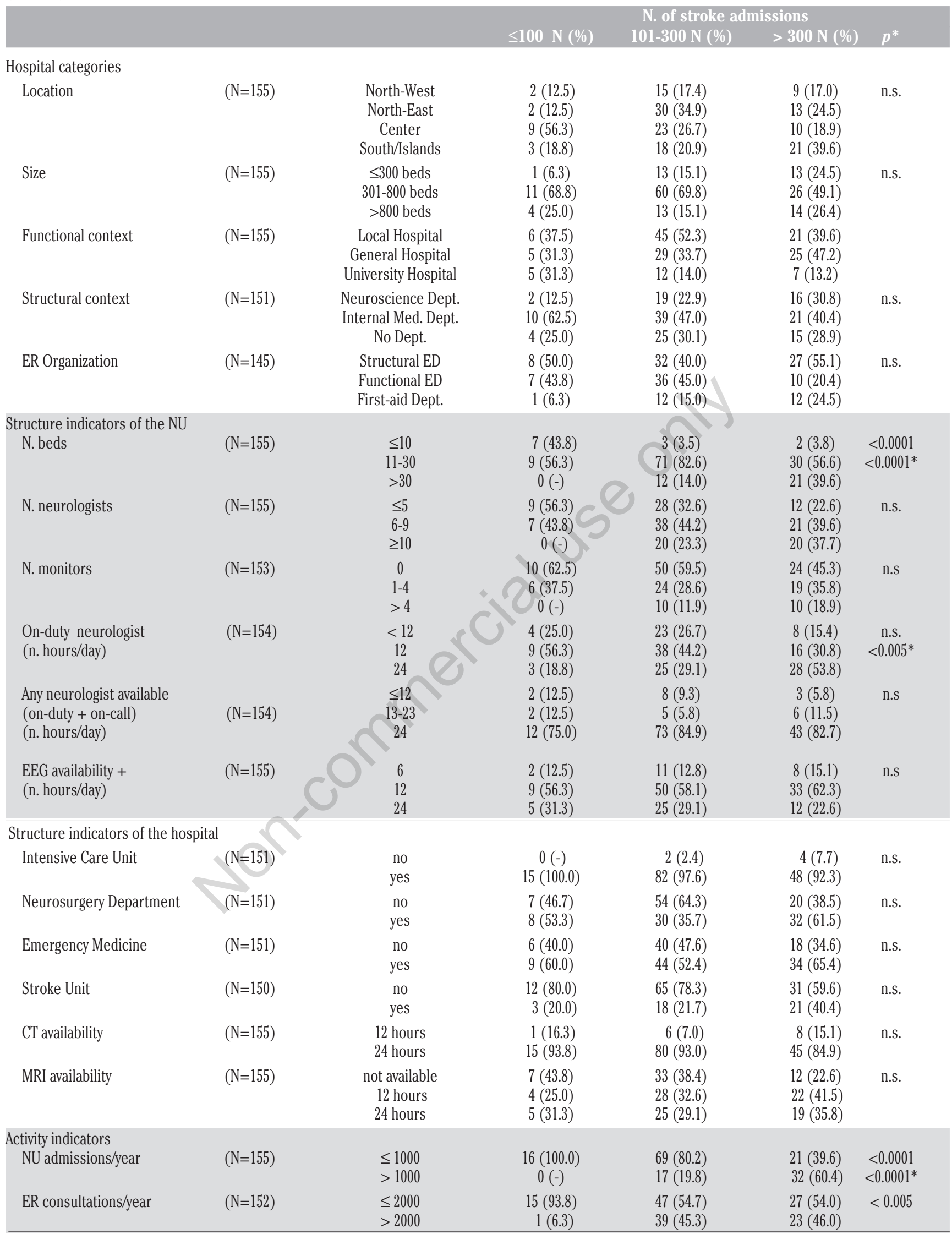

CT, Computerized Tomography; ED, Emergency Department; EEG, Electroencephalography; ER, Emergency Room; MRI, Magnetic Resonance Imaging; NU, Neurological Unit $\mathrm{X}^{2}$ test and $\mathrm{X}^{2}$ for trend test $\left(^{*}\right)$. 
Table 2. Hospital categories and structure-activity indicators by relative stroke workload (percentage of admissions for stroke per year/total admissions to each $\mathrm{NU}$ per year) $(\mathrm{N}=155)$.

\begin{tabular}{|c|c|c|c|c|c|c|}
\hline \multirow{2}{*}{$\leq$} & & & \multicolumn{4}{|c|}{ Relative stroke workload } \\
\hline & & & $\leq 20 \mathrm{~N}(\%)$ & $21-40$ N (\%) & $>40 \mathrm{~N}(\%)$ & $p^{*}$ \\
\hline \multicolumn{7}{|l|}{ Hospital categories } \\
\hline \multirow[t]{4}{*}{ Location } & \multirow[t]{4}{*}{$(\mathrm{N}=155)$} & North-West & $3(8.3)$ & $15(17.1)$ & $8(25.8)$ & \multirow{4}{*}{ n.s. } \\
\hline & & North-East & $11(30.6)$ & $28(31.8)$ & $6(19.4)$ & \\
\hline & & Center & $12(33.3)$ & $20(22.7)$ & $10(32.3)$ & \\
\hline & & South/Islands & $10(27.8)$ & $25(28.4)$ & $7(22.6)$ & \\
\hline \multirow[t]{3}{*}{ Size } & \multirow[t]{3}{*}{$(\mathrm{N}=155)$} & $\leq 300$ beds & $3(8.3)$ & $15(17.1)$ & $9(29.0)$ & \multirow{3}{*}{ n.s. } \\
\hline & & $301-800$ beds & 24 (66.7) & $55(62.5)$ & $18(58.1)$ & \\
\hline & & $>800$ beds & $9(25.0)$ & $18(20.5)$ & $4(12.9)$ & \\
\hline \multirow[t]{3}{*}{ Functional context } & \multirow[t]{3}{*}{$(\mathrm{N}=155)$} & Local Hospital & & $13(36.1)$ & $42(47.7)$ & \multirow{3}{*}{$\begin{array}{c}17(54.8) \\
\text { n.s. }\end{array}$} \\
\hline & & General Hospital & $13(36.1)$ & $35(39.8)$ & $11(35.5)$ & \\
\hline & & University Hospital & $10(27.8)$ & $11(12.5)$ & $3(9.7)$ & \\
\hline \multirow[t]{3}{*}{ Structural context } & \multirow[t]{3}{*}{$(\mathrm{N}=151)$} & Neuroscience Dept. & $11(32.4)$ & $15(17.2)$ & $11(23.9)$ & \multirow{3}{*}{ n.s. } \\
\hline & & Internal Med. Dept. & $12(35.3)$ & $49(56.3)$ & $9(30.0)$ & \\
\hline & & No Dept. & $11(32.4)$ & $23(26.4)$ & $10(33.3)$ & \\
\hline \multirow[t]{3}{*}{ ER Organization } & \multirow[t]{3}{*}{$(\mathrm{N}=145)$} & Structural ED & $18(54.6)$ & $33(40.2)$ & $16(53.3)$ & \\
\hline & & Functional ED & $11(33.3)$ & $34(41.5)$ & $8(26.7)$ & n.s. \\
\hline & & First-aid Dept. & $4(12.1)$ & & & \\
\hline Structure indicators of the NU & & & & & & \\
\hline N. beds & $(\mathrm{N}=155)$ & & $4(11.1)$ & $4(5.6)$ & $4(12.9)$ & \\
\hline & & $11-30$ & $24(66.7)$ & $61(69.3)$ & $25(80.7)$ & n.s. \\
\hline & & $>30$ & $8(22.2)$ & $23(26.1)$ & $2(6.5)$ & \\
\hline N. monitored beds & $(\mathrm{N}=153)$ & 0 & $25(71.4)$ & $48(55.2)$ & $11(35.5)$ & \\
\hline & & $1-4$ & $7(20.0)$ & $28(32.2)$ & $14(45.2)$ & $=0.008^{*}$ \\
\hline & & $>4$ & $3(8.6)$ & $11(12.6)$ & $6(19.4)$ & \\
\hline N. neurologists & $(\mathrm{N}=155)$ & $\leq 5$ & $10(27.8)$ & $29(33.0)$ & $10(32.3)$ & \\
\hline & & $6-9$ & $17(47.2)$ & $37(42.1)$ & $12(38.7)$ & n.s. \\
\hline & & $\leq \geq 10$ & $9(25.0)$ & $22(25.0)$ & $9(29.0)$ & \\
\hline On-duty neurologist & $(\mathrm{N}=154)$ & $<12$ & $8(22.2)$ & $22(25.3)$ & $5(16.1)$ & \\
\hline (n. hours/day) & & 12 & $16(44.4)$ & $36(41.4)$ & $11(35.5)$ & n.s. \\
\hline & & 24 & $12(33.3)$ & $29(33.3)$ & $15(48.4)$ & \\
\hline Any neurologist available & & $\leq 12$ & $3(8.3)$ & $9(10.3)$ & $1(3.2)$ & \\
\hline (on-duty or on-call) & $(\mathrm{N}=154)$ & $13-23$ & $2(5.6)$ & $8(9.2)$ & $3(9.7)$ & n.s. \\
\hline (n. hours/day) & & 24 & $31(86.1)$ & $70(80.5)$ & $27(87.1)$ & \\
\hline EEG availability & $(\mathrm{N}=155)$ & 6 & $4(11.1)$ & $10(11.4)$ & $7(22.6)$ & \\
\hline (n. hours/day) & & 12 & $19(52.8)$ & $54(61.4)$ & $19(61.3)$ & n.s. \\
\hline & & 24 & $13(36.1)$ & $24(27.3)$ & $5(16.1)$ & \\
\hline Structure indicators of the Hos & & & & & & \\
\hline Intensive Care Unit & $(\mathrm{N}=151)$ & no & $1(2.9)$ & $3(3.5)$ & $2(6.5)$ & \\
\hline & & yes & $33(97.1)$ & $83(96.5)$ & $29(93.6)$ & n.s. \\
\hline Neurosurgery Department & $(\mathrm{N}=151)$ & no & $16(47.1)$ & $49(57.0)$ & $16(51.6)$ & \\
\hline & & yes & $18(52.9)$ & $37(43.1)$ & $15(48.4)$ & n.s. \\
\hline Emergency Medicine & $(\mathrm{N}=151)$ & no & $14(41.2)$ & $40(46.5)$ & $10(32.3)$ & \\
\hline & & yes & $20(58.8)$ & $46(53.5)$ & $21(67.7)$ & n.s. \\
\hline Stroke Unit & $(\mathrm{N}=150)$ & no & 30 (88.2) & $60(70.6)$ & $18(58.1)$ & n.s. \\
\hline & & yes & 4 (11.8) & $25(29.4)$ & $13(41.9)$ & $=0.007^{*}$ \\
\hline CT availability & $(\mathrm{N}=155)$ & 12 hours & $2(5.6)$ & $9(10.2)$ & $4(12.9)$ & n.s. \\
\hline & & 24 hours & $34(94.4)$ & $79(89.8)$ & $27(87.1)$ & \\
\hline MRI availability & $(\mathrm{N}=155)$ & not available & $11(30.6)$ & $33(37.5)$ & $8(25.8)$ & \\
\hline & & 12 hours & $10(27.8)$ & $30(34.1)$ & $14(45.2)$ & n.s. \\
\hline & & 24 hours & $15(41.7)$ & $25(28.4)$ & $9(29.0)$ & \\
\hline Activity indicators & & & & & & \\
\hline NU admissions/year & $(\mathrm{N}=152)$ & $\leq 1000$ & $23(63.9)$ & $60(68.2)$ & $23(74.2)$ & n.s. \\
\hline & & $>1000$ & $13(36.1)$ & $28(31.8)$ & $8(25.8)$ & \\
\hline ER consultations/year & $(\mathrm{N}=152)$ & $\leq 2000$ & $28(77.8)$ & $48(55.8)$ & $13(43.3)$ & n.s. \\
\hline & & $>2000$ & $8(22.2)$ & $38(44.2)$ & $17(56.7)$ & $<0.005^{*}$ \\
\hline
\end{tabular}

CT, Computerized Tomography; ED, Emergency Department; EEG, Electroencephalography; ER, Emergency Room; MRI, Magnetic Resonance Imaging; NU, Neurological Unit

$\mathrm{X}^{2}$ test and $\mathrm{X}^{2}$ for trend test $\left({ }^{*}\right)$. 
able in NU admitting larger numbers of stroke patients. Second, two other requirements for PSC are widely lacking in Italy: bed monitoring (55\% of NU), and 24/7 on-duty or on-call neurologists (17\%). Surprisingly, in $13 \mathrm{NU}(8 \%)$ a neurologist was available for less than 12 hours per day. Third, the paucity of neuroscience departments and stroke units represents a serious limitation for Italian NU activities, though the same is found in France, where only $30 \%$ of hospitals with NU had a stroke unit. ${ }^{12}$ A recent Italian survey found only $9 \%$ of wards admitting $>50$ stroke patients/ year equipped with a stroke unit, ${ }^{3}$ which is less than in many other countries. ${ }^{18}$ This is even more remarkable when considering that acute clinical conditions like ischemic stroke require timely treatments. ${ }^{1}$ This is a prerequisite to devise more efficient and comprehensive programs aimed at providing all Italian hospitals with a 24-hour active ER neurological consultation and neuroimaging, hopefully organized in structural departments.

Our study has some strengths and several limitations. The major strength is the extensive coverage of the whole of Italy. The number of respondents was sufficient to obtain meaningful information, and there were no major differences in the responders compared to the non-responders. The first major limitation is the unknown validity of the information obtained from the local participants. Although the regional coordinators had frequent contacts with the neurologists in charge from each participating hospital and made an effort to have fairly complete and high quality data, no formal measure was taken to verify the validity and reliability of the sources. The second limitation is the lack of comparative findings from the hospitals with no NU. In fact, more than $50 \%$ of stroke patients in Italy are still admitted to general medical wards; only 42,361 of the 123,310 stroke patients discharged in a year from the Italian hospitals were discharged from the $\mathrm{NU}$ responders in our survey (corresponding to $71 \%$ of all the Italian NU). The third limitation is that our data were collected for the year 2002 ; however, we think that hospital neurological resources for stroke have changed little over recent years in Italy. The EUSI survey reports that in 2006 only $6 \%$ of 112 Italian hospitals admitting more than 50 acute stroke patients per year met the criteria for Comprehensive or Primary Stroke Center, and in 53\% even the minimum level was not available. ${ }^{11}$

In conclusion, this survey shows that stroke management in Italy is largely unrelated to several structural and functional indicators of hospital efficiency.

\section{References}

1. Hanley D, Hacke W. Critical care and emergency medicine neurology in stroke. Stroke 2005;36:205-7.

2. Wardlaw JM, Farrall AJ. Diagnosis of stroke on neuroimaging. $\mathrm{Br}$ med $\mathrm{J}$ 2004;328: 655-6.

3. Candelise L, Gattinoni M, Bersano A, et al. on behalf of the PROSIT Study Group. Stroke-unit care for acute stroke patients: an observational follow-up study. Lancet 2007;369:299-305.

4. Moulin T, Sablot D, Vidry E, et al. Impact of emergency room neurologists on patient management and outcome. Eur Neurol 2003;50:207-14.

5. Garcia-Ramos R, Moreno T, Camacho A, et al. Analisis de la atención neurologica en la urgencia del Hospital Doce de Octubre. Neurologia 2003;18:431-8.

6. Carroll C, Zajicek J. Provision of 24 hour acute neurology care by neurologists: manpower requirements in the UK. J Neurol Neurosurg Psychiatry 2004;75:406-
9.

7. ASSR. I principali dati della sanità. Monitor, Elementi di analisi e osservazione del sistema salute. 2006;16:23.

8. www.ministerosalute.it/ programmazione/ sdo/ric_informazioni/sceltadia.jsp

9. Janca A, Aarli JA, Prilipko L, Dua T, Saxena S, Saraceno BJ. WHO/WFN Survey of neurological services: a worldwide perspective. J Neurol Sci 2006;247:29-34.

10. Leys D, Ringelstein EB, Kaste M, Hacke W. The main components of stroke unit care: results of a European expert survey. Cerebrovasc Dis 2007;23:344-52.

11. Leys D, Ringelstein EB, Kaste M, Hacke W, for the Executive Committee of the European Stroke Initiative. Facilities Available in European hospitals treating stroke patients. Stroke 2007;38:2985-91.

12. Bonnaud I, Hommel M, Woimant F, for the Group of Evaluation of Professional Practices, French Neurovascular Society. Stroke care in France in 2005: a national survey. Cerebrovasc Dis 2007;23:5.

13. Busse 0. Stroke units and stroke services in Germany. Cerebrovasc Dis 2003;15:8-10.

14. Asplund K. Stroke care in the UK - is it good enough? Lancet Neurol 2002;1:341.

15. De Falco FA, Sterzi R, Toso V, et al. The neurologist in the emergency department. An Italian Nationwide Epidemiological Survey. Neurol Sci 2008;29:67-75.

16. SAS Institute Inc. SUGI supplemental library user's guide. 8th ed. Cary, NC: SAS Institute 1999-2001.

17. Brainin M, Bornstein N, Boysen G, Demarin B. Acute neurological stroke care in Europe. Results of the European stroke care inventory. Eur J Neurol 2000;7:5-10.

18. Bersano A, Candelise L, Sterzi R, and the PROSIT. Study Group. Stroke Unit care in Italy. Results from PROSIT (Project on Stroke Services in Italy). A nationwide study. Neurol Sci 2006;27:332-9. 